\title{
A Comparison of the Latest Window Modeling Methods in EnergyPlus
}

\author{
Christian Kohler ${ }^{1}$, Peter Lyons ${ }^{2}$, Robert G. Hart ${ }^{1}$, Charlie D. Curcija ${ }^{1}$ \\ ${ }^{1}$ Lawrence Berkeley National Laboratory, Berkeley, United States of America \\ ${ }^{2}$ Peter Lyons \& Associates, Kaleen, Australia
}

\begin{abstract}
The accuracy and sensitivity of fenestration modeling in EnergyPlus (DOE 2019) is very important since fenestration is typically the dominant envelope load. New technologies, such as room-side low-E coatings and vacuum glazing, can challenge models that were developed before these technologies existed. In this report, we examine the sensitivity of EnergyPlus results to six available window models, including two simplified models that utilize known overall $\mathrm{U}$ and SHGC of the window (simple bulk properties) and creates layer-bylayer descriptions for fenestration system. One of these simplified methods also takes into account the type of frame and number of glazing layers if available.

A range of window performance levels are modeled with the residential prototype buildings developed by Pacific Northwest National Laboratory, based on DOE's Residential Reference Building Models. Building models include high- and low thermal mass versions to understand the sensitivity of results to fenestration solar transmittance variations. Results from six windowmodeling methodologies are compared, conclusions are drawn, and recommendations are presented.
\end{abstract}

\section{Introduction}

It is important for fenestration product designers and simulators to better understand the differences between the range of available models so that product variations can be accounted for accurately, while also using the most efficient simulation methods possible. EnergyPlus Version 9 (DOE, 2018) offers various powerful, alternative methods for defining windows and other fenestration systems in modeled buildings. This has occurred in response to the need to model new and evolving glazing and frame technologies, including highly insulating frames, spectrally selective low-E coatings and exposed interior low-E coatings. Lyons et al (2010) published a study of window-modeling options available at the time in EnergyPlus Version 4. No comprehensive comparison of numerous alternative fenestration modeling methods available in EnergyPlus has been published since. This leaves practitioners in the dark about the applicability of various models and the merits of each one.

Our paper presents an update on EnergyPlus fenestration modeling. Techniques reviewed include the Simple Window Model, legacy spectral and spectrally averaged models, as well as the detailed Bi-Directional Scattering Distribution Function (BSDF). In addition, a recently published report and software tool (ASHRAE 2016) allows users to input a handful of known window parameters. From these inputs, reverse-engineering 'smart' algorithms generate detailed parameters that can be input to any building simulation engine, including EnergyPlus.

\section{Methods}

EnergyPlus provides several options for modeling windows and shading systems. Some models were added to EnergyPlus to expand and improve the modeling of shading systems. These models can often also be used to model glazing systems only. The focus of this paper is on modeling glazing systems without shading devices. Originally, only two models were available, and they were based on the ISO 15099 standard. These models and implementations will be referred to as "Winkelmann" (Winkelmann 2001). One Winkelmann model uses spectral glazing data (Winkelmann Spectral), the second model uses spectrally average data (Winkelmann Average). The spectrally averaged model includes one value for the solar transmittance and one for the visible transmittance. The spectral model on the other hand often has transmittance data for 100-400 wavelengths. Starting with EnergyPlus version 4 a "Simple Window" model was added (Arasteh et al. 2009), followed by several other models, sequentially implemented up to version 9 . These added models are:

- BSDF model (Curcija et al. 2018)

- ASHRAE 1588-RP model (ASHRAE 2016)

- ASHWAT (Wright et al. 2011)

- WinCalc BSDF Engine models (Curcija et al. 2018) With the exception of the WinCalc Engine, all these models were implemented in FORTRAN in EnergyPlus before the conversion to $\mathrm{C}++$ (version 8.2). WinCalc Engine was a 'from scratch' implementation in $\mathrm{C}++$ of the ISO 15099 and BSDF models.

The BSDF model was developed to more accurately model optically complex shading and glazing systems such as fritted glass, woven shades, cellular shades etc. However, shading layers were not included in our study. The categories labelled "BSDF Model" refer to the most comprehensive set of window-modeling algorithms available to EnergyPlus users. The Winkelman code provides only the original ISO 15099 implementation of diffuse (scattering) radiation, where the propagation of 
diffuse radiation is treated the same way as the distribution of specular radiation, which results in some inaccuracies. The WinCalc code implements a more accurate Matrix-based method (Klems 1993a; 1993b), or it can divide the radiation propagation into three parts, direct-to-direct, direct-to-diffuse and diffuse-to-diffuse. The improvement in accuracy in the BSDF method, of course is realized only for scattering glazing and shading. Another nuance in modeling windows in EnergyPlus is that outside software tools (e.g., LBNLs WINDOW) can "pre-model" windows and export spectrally averaged information (available at discrete angles of incidence) to EnergyPlus. This approach is slightly less accurate than performing full spectral calculation for each hour in model year but is also faster and requires less detailed input data.

For this paper, we chose six different models/approaches as representative of commonly used windows models in EnergyPlus:

$\begin{array}{ll}\text { Model 1. } & \text { WinCalc BSDF (baseline) } \\ \text { Model 2. } & \text { Original BSDF } \\ \text { Model 3. } & \text { Winkelmann Spectral } \\ \text { Model 4. } & \text { Winkelmann Average } \\ \text { Model 5. } & \text { Simple Window Model ("SWM") } \\ \text { Model 6. } & \text { ASHRAE 1588 model ("1588") }\end{array}$

The WinCalc BSDF model is the most detailed and recently implemented model in EnergyPlus and for this reason was selected as the baseline model.

The simplest of available window modeling methods, in terms of computational effort, is Model 5, the "Simple Window Model". This model allows the user to define a vertical window in an EnergyPlus building model using only the window's whole-system U-factor, solar heat gain coefficient and (optionally) its visible transmittance. On the opposite side of the computational spectrum is the center-of-glass model based on WINDOW 7 Bidirectional Scattering Distribution Functions (BSDF), in conjunction with a detailed 2D frame thermal transmittance calculation. This model considers the full spectral distribution of solar radiation through fenestration layers. These models handle major glazing and frame technologies very differently. Generic frame conductances were used in this study.

The ISO 15099 model for calculating energy performance indices of glazing and windows, which is the basis for both Winkelman models, Spectral and Averaged (models 1 and 2) is described in both ISO standard 15099 (ISO 2003) and a paper by Winkelmann (Winkelmann 2001). EnergyPlus technical documentation (DOE 2018) also includes methodology details. WinCalc and BSDF methodology is described in full detail in LBNL's WINDOW technical documentation (Curcija et al. 2018). Additional information is available in several technical papers (Klems 1993a; 1993b), as well as ISO 15099.
ASHRAE (2016) published a research report and software tool, generally referred to in this paper as 'ASHRAE 1588'. The tool accepts a limited number of user inputs and uses intelligent search algorithms to produce a detailed, physically realistic description of the fenestration system of interest. The program is designed to be used in a stand-alone mode to produce a text file containing information suitable to be input to any popular building simulation engine, including EnergyPlus. Used optimally, it produces text descriptions of fenestration systems with U-factor and SHGC that match the target (original) values to within 4 percent or better.

Upon converging to a solution, ASHRAE 1588 generates two output files. The first is a 'DOE-2 report'. This is a text report describing the frame and glazing combination of a complete window that can be read by the DOE-2 building simulation program (U.S Department of Energy 1976-). The second output is a JSON file that contains very detailed data on the thermal and solar optical properties of the window's components. Neither of these output files can be read by EnergyPlus. Therefore, a translation process was used to convert their information into a unique EnergyPlus 'WindowDataFile' object, for each window of interest. The WindowDataFile object is also a reporting option provided by the WINDOW 7 program (LBNL 2019b).

\section{Description of ASHRAE 1588 process}

The five windows in Table 1 were processed using the ASHRAE 1588 solver software. For each window, the solver was given up to seven inputs:

- System U-factor as modeled in WINDOW 7.7.1, including frame, edge and center-glass effects.

- System SHGC (g-value) as modeled in WINDOW 7.7.1, including frame and center-glass effects. Edge SHGC is equal to center-glass SHGC in accordance with the ISO 15099 alternative method, as used by NFRC procedures.

- Fenestration type (fixed window).

- Number of glazing layers (1, 2, 3 or 4).

- Spacer material (chosen from a list of 6 discrete options).

- Frame material (chosen from a list of 6 discrete options).

- Frame width (i.e. 'projected frame dimension' in plane parallel to glass).

The 1588 solver is flexible and can be initialized with the user's choice of input values for discrete parameters above, if it is found necessary to converge to a solution. Table 1 lists the parameters assigned to each window and used as inputs to the solver.

\section{Outputs from the ASHRAE 1588 Solver}

Table 2 shows results from the ASHRAE 1588 solver and compares them with the original input windows modeled in WINDOW 7.7.1. 
Table 1: Window properties and ASHRAE 1588 inputs. TB denotes thermal break.

\begin{tabular}{|c|l|c|c|c|c|c|c|c|c|}
\hline \multicolumn{1}{|c|}{ Description } & $\begin{array}{c}\text { U-factor } \\
\left(\mathbf{W} / \mathbf{m}^{2}-\mathbf{K}\right)\end{array}$ & $\begin{array}{c}\text { sHGC } \\
(-)\end{array}$ & $\begin{array}{c}\text { vT } \\
-\end{array}$ & Type & $\begin{array}{c}\text { Glazing } \\
\text { layers }\end{array}$ & $\begin{array}{c}\text { Spacer } \\
\text { Material }\end{array}$ & $\begin{array}{c}\text { Frame } \\
\text { Material }\end{array}$ & $\begin{array}{c}\text { Frame } \\
\text { width } \\
(\mathbf{m m})\end{array}$ \\
\hline 1 & Double clear, aluminium frame & 3.16 & 0.67 & 0.70 & Fixed & 2 & $\mathrm{n} / \mathrm{a}$ & Metal TB & 50.8 \\
\hline 2 & Double, tint, wood frame & 2.69 & 0.33 & 0.19 & Fixed & 2 & $\mathrm{n} / \mathrm{a}$ & Wood/Vinyl & 69.8 \\
\hline 3 & Double, low-e, wood frame & 1.95 & 0.33 & 0.55 & Fixed & 2 & $\mathrm{n} / \mathrm{a}$ & Wood/Vinyl & 69.8 \\
\hline 4 & Triple, insulated frame & 0.91 & 0.30 & 0.50 & Fixed & 3 & Insulated & Insulated & 69.8 \\
\hline 5 & Double, room-side low-e, vinyl frame & 1.19 & 0.18 & 0.41 & Fixed & 2 & Insulated & Wood/Vinyl & 69.8 \\
\hline
\end{tabular}

Table 2: Comparison of ASHRAE 1588 (Model 6) outputs versus original (target) windows modeled in WINDOW 7.7.1

\begin{tabular}{|c|c|c|c|c|c|c|}
\hline ID & $\begin{array}{c}\mathbf{U} \\
\text { target }\end{array}$ & $\begin{array}{c}\mathbf{U} \\
\mathbf{1 5 8 8} \\
(\text { Model } \\
\text { ) }\end{array}$ & $\begin{array}{c}\text { Diff } \\
\mathbf{\%}\end{array}$ & $\begin{array}{c}\text { SHGC } \\
\text { target }\end{array}$ & $\begin{array}{c}\text { SHGC } \\
\mathbf{1 5 8 8} \\
\text { (Model } \\
\text { 6) }\end{array}$ & $\begin{array}{c}\text { Diff. } \\
\mathbf{\%}\end{array}$ \\
\hline 1 & 3.16 & 3.20 & 1.2 & 0.67 & 0.65 & -2.4 \\
\hline 2 & 2.69 & 2.72 & 1.0 & 0.33 & 0.33 & -0.3 \\
\hline 3 & 1.95 & 1.99 & 2.2 & 0.33 & 0.34 & 2.7 \\
\hline 4 & 0.91 & 0.93 & 2.6 & 0.30 & 0.31 & 2.7 \\
\hline 5 & 1.19 & 1.23 & 3.1 & 0.18 & 0.19 & 3.8 \\
\hline
\end{tabular}

\section{Building Model}

Pacific Northwest National Laboratory (PNNL) has created a set of residential (and commercial) prototypical house models for EnergyPlus for various cities in the US. The models are created to match various building code versions. For this study the 2006 IECC (International Energy Conservation Code) version of the models were used. This year was chosen because it provides an average of older existing homes and new construction home insulation levels. There are models with different heating and cooling systems, and different foundation types. The model with a slab foundation, gas furnace and electrical air conditioning was used. There is a bug in the default PNNL models for homes with a slab foundation which results in the thermal mass of the slab not being accounted for in the calculations. This bug was fixed for the simulations in this study.

Three different locations where chosen. Minneapolis, Minnesota as a cold, heating-dominated climate. Phoenix, Arizona as a hot, cooling-dominated climate, and Rome, Italy as an example of a mixed heating and cooling climate. The building model for Sacramento was used for the Rome simulation, since the PNNL prototypical homes have only been created for US cities. Sacramento was chosen based on a comparison of heating and cooling degree days between Rome and US cities. The construction and insulation levels are typical for Sacramento, California, but the climatic conditions from Rome are used.

Typical wall and slab constructions in the US are relatively low mass. In order to determine if building mass significantly impacts relative performance of the window simulation engines, a high mass version of the
Sacramento home was created. The high mass Sacramento building utilizes a $15 \mathrm{~cm}$ slab in place of a 10 $\mathrm{cm}$ slab and $10 \mathrm{~cm}$ concrete in place of $1.8 \mathrm{~cm}$ drywall on the exterior walls. This home was also modeled with the Rome climate.

\section{Simulated Windows}

Model 5, the Simple Window Model (Arasteh et al 2009) was designed to work with single- and double-glazed windows. The development did not consider triple-glazed windows. It also did not include windows with a roomfacing (surface 4) low-e coating. In this study we did include a triple-glazed window (\#4) and a window with a coating on the room-facing surface (\#5)

In order to compare the performance of various methods for modeling windows in EnergyPlus, five different windows were defined, see Table 1 . These windows range from simple double-glazed without any coatings and gas fills in an aluminum frame to triple glazed, krypton filled, low-e coated windows with a highly insulating frame. All windows were simulated using LBNL WINDOW 7.7.1. The properties in Table 1 were calculated at a standard size of $1200 \mathrm{~mm}$ wide by $1500 \mathrm{~mm}$ tall, using the calculations in accordance to ISO 15099.

Even though windows 2 and 3 have the same SHGC, the details of the solar heat gain for these two windows are very different. The Solar Heat Gain Coefficient (SHGC) is composed of two components, the solar transmittance of the glazing and the inward-flowing fraction of the absorbed energy in the glazing layers. For example, for single glazing,

$\mathrm{SHGC}=T_{s}+N_{i} * A_{s}$

where:

$T_{s}=$ Solar transmittance of glazing [-]

$N_{i}$ = Inward-flowing fraction of absorbed radiation [-]

$A_{s}=$ Fraction of solar energy absorbed in glazing layers [-]

Table 3 shows that the inward-flowing fraction of the absorbed energy $\left(N_{i} * A_{s}\right)$ is $55 \%(0.22 / 0.40)$ for window 2 , but only $12.5 \%(0.05 / 0.40)$ for window 3 . The tinted glass in window 2 transmits less solar radiation $\left(T_{s}=0.18\right)$, but a significant portion of this absorbed energy is delivered to the space. The transmitted solar radiation might strike a high thermal mass surface such as the floor or walls. The solar energy will be stored in these high thermal mass surfaces and released at a later time. Solar energy that is 
absorbed in the glass is transmitted directly to the air in the room and will result in an immediate cooling load. Note that the SHGCs in Table 3 are for the glazing portion only (excluding the frame).

The Simple Window Model 5 uses overall SHGC; therefore, it cannot tell the building energy simulation what fraction of the total solar heat gain is direct and how much is indirect. As explained above, this would be expected to lead to a greater variance in simulation outcomes, between different window models, for highmass buildings compared with the spread of outcomes for low-mass buildings.

Table 3: Solar Heat Gain Coefficient components

\begin{tabular}{|c|l|c|c|c|}
\hline ID & \multicolumn{1}{|c|}{ Description } & $\begin{array}{c}\text { SHGC } \\
{[-]}\end{array}$ & $\begin{array}{c}T_{s} \\
{[-]}\end{array}$ & $\begin{array}{c}N_{i} * A_{s} \\
{[-]}\end{array}$ \\
\hline 1 & Double clear & 0.76 & 0.70 & 0.06 \\
\hline 2 & Double, tint & 0.40 & 0.18 & 0.22 \\
\hline 3 & Double, low-e & 0.40 & 0.35 & 0.05 \\
\hline 4 & Triple, low-e & 0.37 & 0.32 & 0.05 \\
\hline
\end{tabular}

\begin{tabular}{|l|l|l|l|l|}
\hline 5 & Double, room low-e & 0.22 & 0.20 & 0.02 \\
\hline
\end{tabular}

\section{Results}

The five windows were simulated with six different models in three different climates, which resulted in 90 EnergyPlus simulations. Additionally, the house construction for Rome was modified with higher thermal mass (in keeping with common Mediterranean building practice), resulting in another 30 simulations, for a total of 120 EnergyPlus simulations.

Total annual site energy in gigajoules (GJ) was calculated by summing the heating, cooling and fan energy. The focus of this study is on the relative performance of various window models in a range of climates for a range of window constructions. Therefore, the results shown are the differences in total energy consumption between the models, not the actual energy consumption. Figures 2 through 5 show the difference between the annual energy consumption of the baseline (WinCalc BSDF) Model 1 and the five other models. Table 4 shows the min, max and mean of the differences for the various models across all simulations.

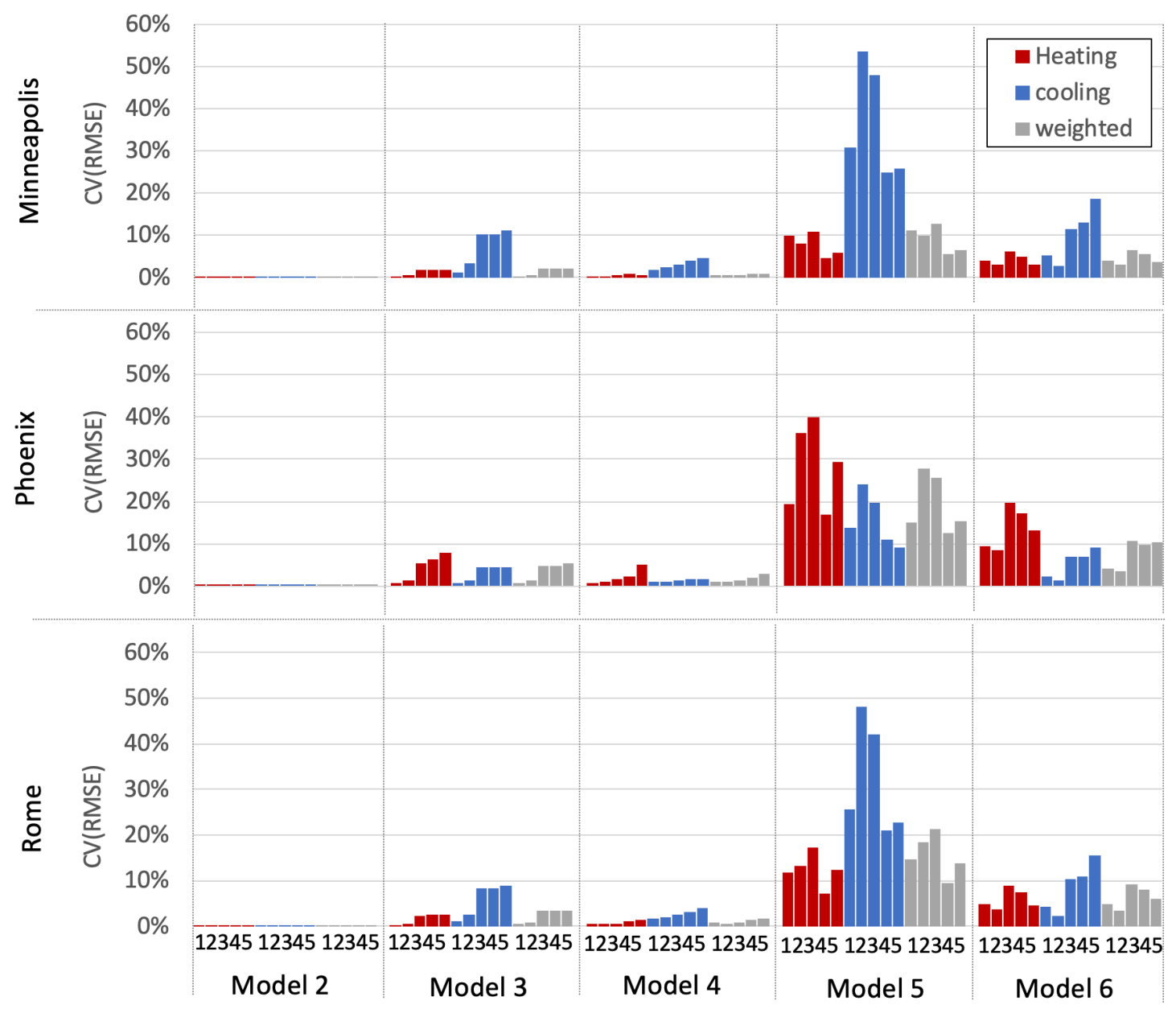

Figure 1: Annual heating, cooling and weighted CV(RMSE) values calculated from hourly results for various window models compared to the WinCalc BSDF Model 1 baseline for Minneapolis, Phoenix and Rome. 


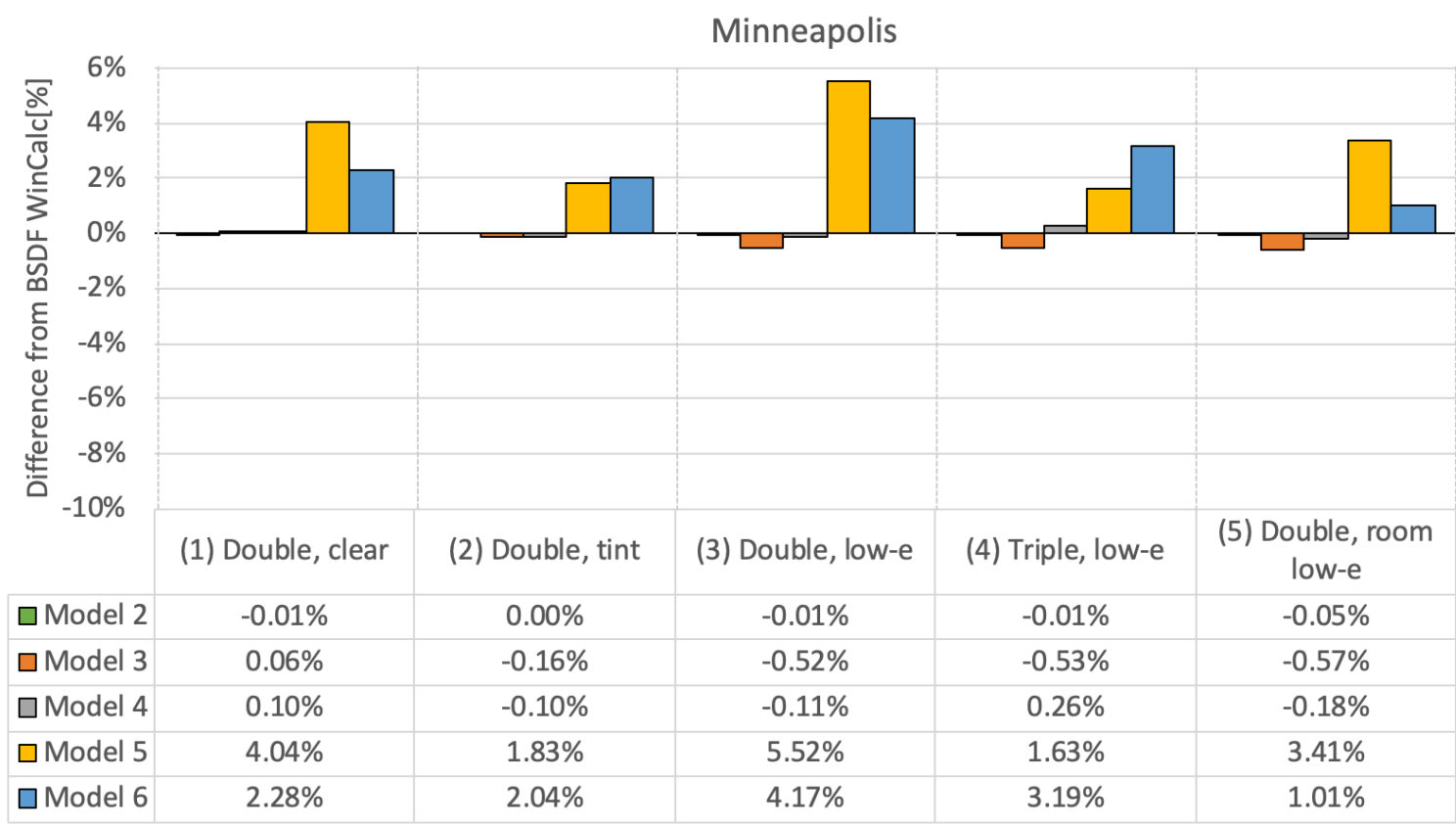

Figure 2: Difference in whole building annual energy consumption for various window models compared to the WinCalc BSDF Model 1 baseline for Minneapolis

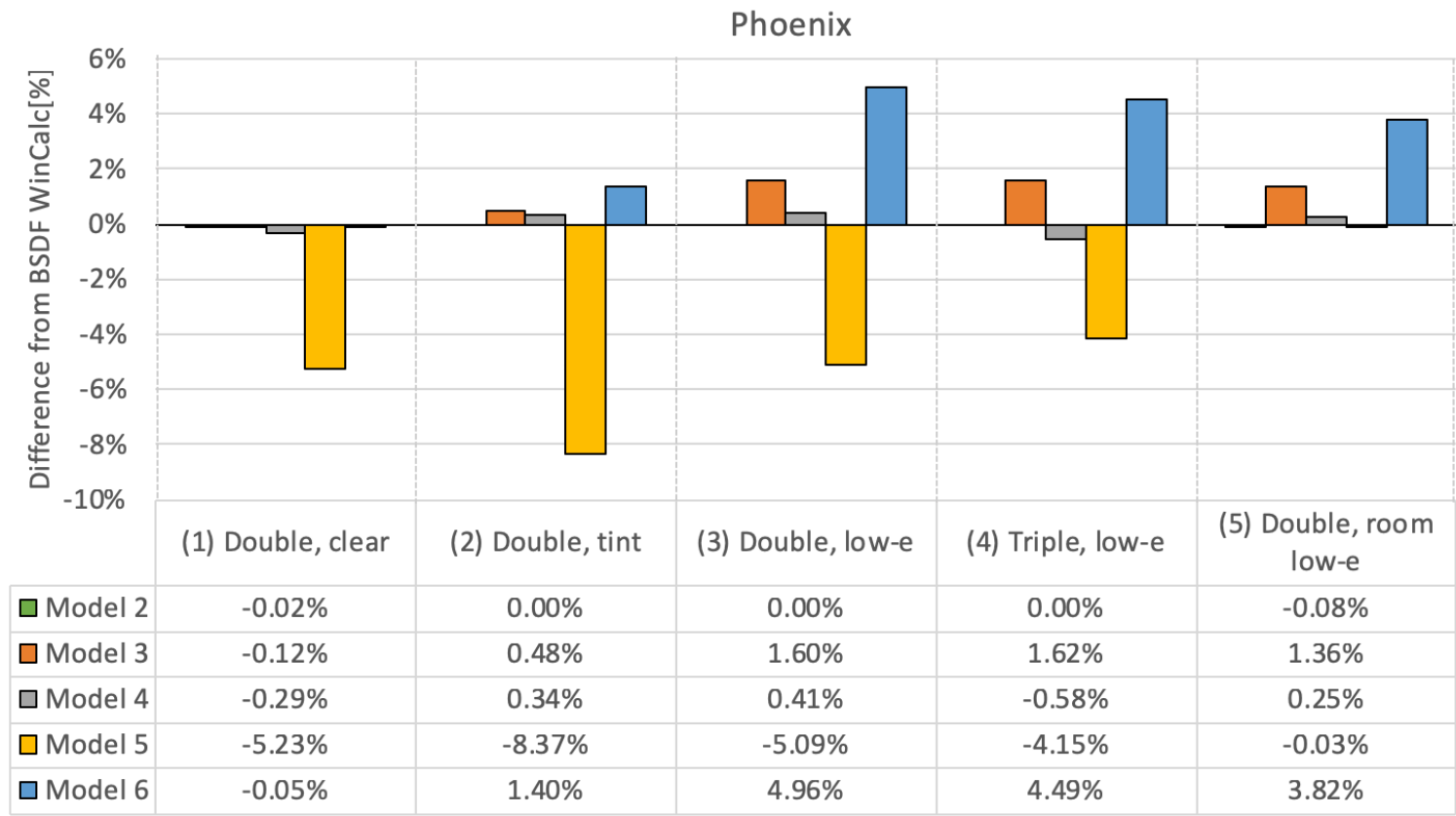

Figure 3: Difference in whole building annual energy consumption for various window models compared to the WinCalc BSDF Model 1 baseline for Phoenix 
Rome

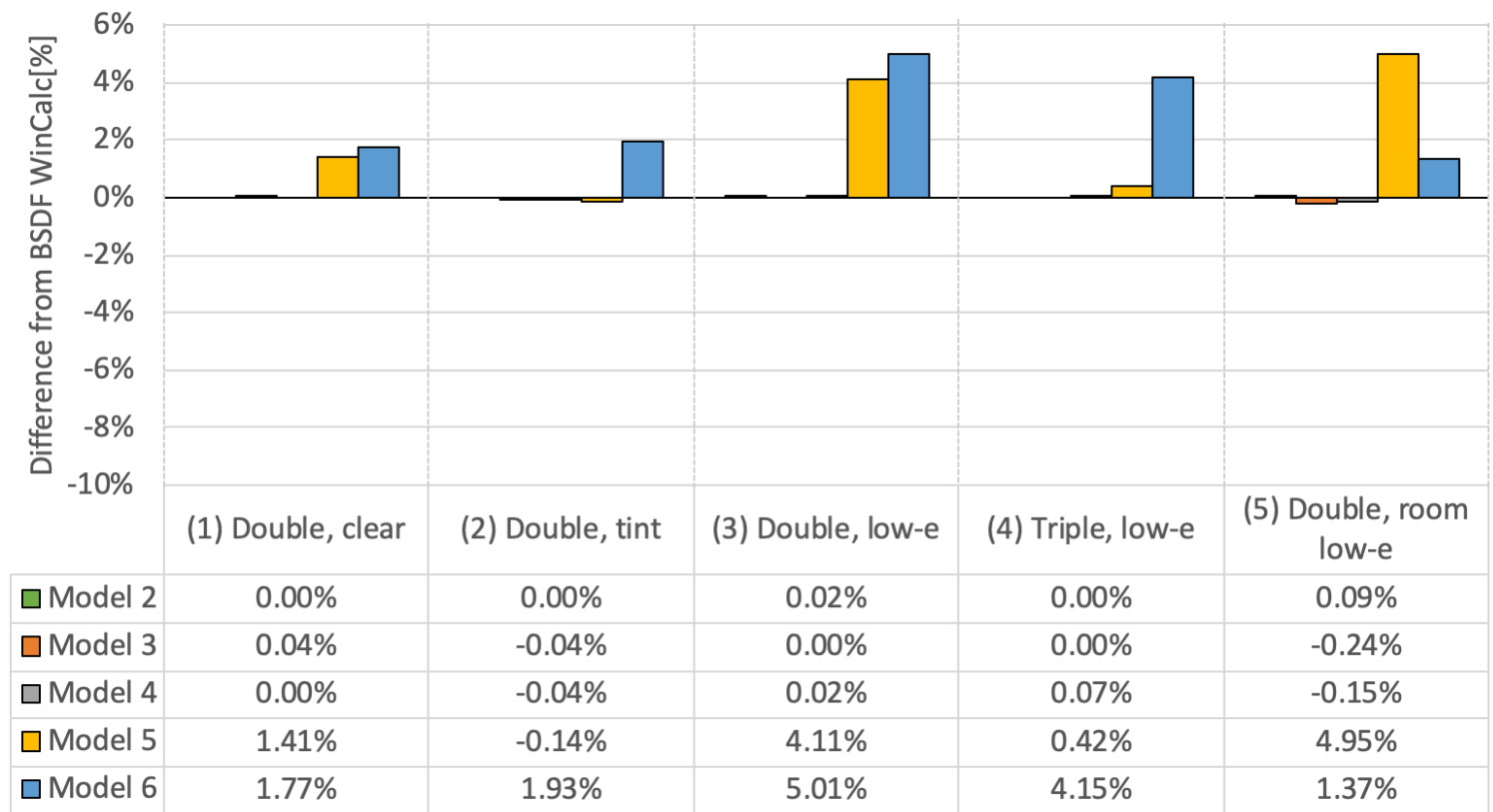

Figure 4: Difference in whole building annual energy consumption for various window models compared to the WinCalc BSDF Model 1 baseline for Rome

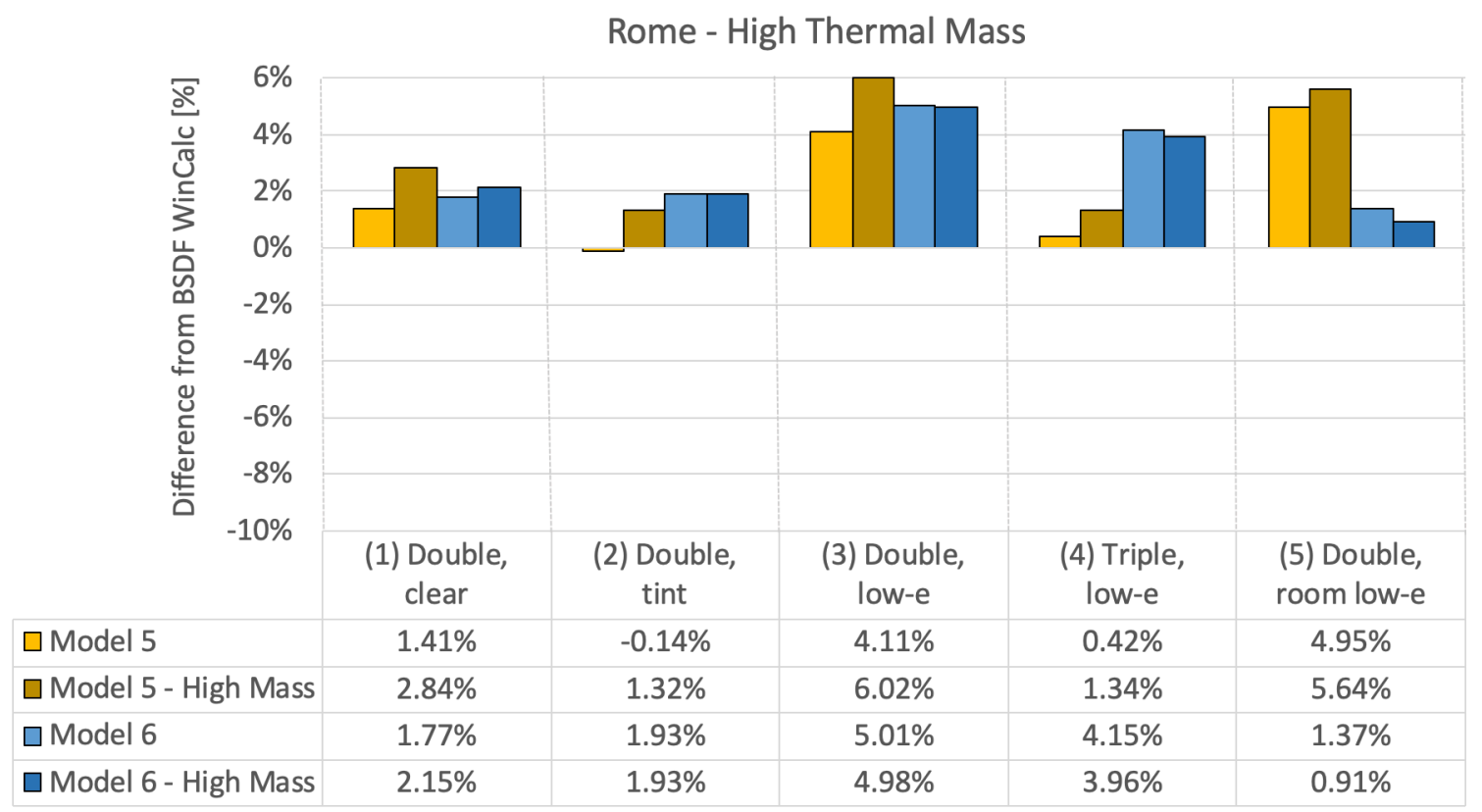

Figure 5: Difference in whole building annual energy consumption for the Simple (Model 5) and 1588 (Model 6) window models compared to the WinCalc BSDF baseline Model 1 for a regular and high thermal mass house in Rome. 
In addition to annual site energy, hourly heating and cooling energy results were compared between the various models by calculating the coefficient of variance of the root mean square error CV(RMSE). CV(RMSE) (Ruiz 2017) is commonly used in comparing simulation and measurement results, but can also be used to compare different models. Because the difference between the models are squared CV(RMSE) does not cancel out positive and negative errors. Criteria for hourly model calibration range from $\mathrm{CV}(\mathrm{RMSE})<20 \%$ (IPMVP) to $\mathrm{CV}(\mathrm{RMSE})<30 \%$ (ASHRAE Guideline 14 and FEMP) as described in Ruiz (2017). WinCalc BSDF Model 1 was used as the baseline model.

All the EnergyPlus input files, and results are publicly available at the following location: https://github.com/LBNL-ETA/IBPSA-2019-windowspaper

Table 4: Annual site energy differences from baseline Model 1 (BSDF WinCalc) for all cities and all windows.

\begin{tabular}{|l|c|c|c|}
\hline \multirow{2}{*}{ Model } & \multicolumn{3}{|c|}{$\begin{array}{c}\text { Difference from baseline } \\
\text { for annual site energy }\end{array}$} \\
\cline { 2 - 4 } & Min & Max & Mean \\
\hline Model 2 & $-0.1 \%$ & $0.1 \%$ & $0.0 \%$ \\
\hline Model 3 & $-0.6 \%$ & $1.6 \%$ & $0.1 \%$ \\
\hline Model 4 & $-0.6 \%$ & $0.4 \%$ & $0.0 \%$ \\
\hline Model 5 & $-8.4 \%$ & $6.0 \%$ & $1.1 \%$ \\
\hline Model 6 & $-0.1 \%$ & $5.0 \%$ & $2.8 \%$ \\
\hline
\end{tabular}

Table 5: Weighted CV(RMSE) Differences from baseline Model 1 (BSDF WinCalc) for all cities and all windows.

\begin{tabular}{|l|c|c|c|}
\hline \multirow{2}{*}{ Model } & \multicolumn{3}{|c|}{ Weighted CV(RMSE) } \\
\cline { 2 - 4 } & Min & Max & Mean \\
\hline Model 2 & $0.0 \%$ & $0.2 \%$ & $0.0 \%$ \\
\hline Model 3 & $0.3 \%$ & $5.5 \%$ & $2.4 \%$ \\
\hline Model 4 & $0.5 \%$ & $2.8 \%$ & $1.2 \%$ \\
\hline Model 5 & $5.6 \%$ & $27.9 \%$ & $15.2 \%$ \\
\hline Model 6 & $3.0 \%$ & $10.6 \%$ & $6.2 \%$ \\
\hline
\end{tabular}

\section{Discussion}

\section{Annual Site Energy}

The largest difference for Model 5 (Simple Window Model) occurs for window \#2 (Double, tint) in Phoenix. The difference between the baseline Model 1 (BSDF WinCalc) and Model 5 is $-8.4 \%$. Window \#2 has a dark tinted glass layer on the inside. This configuration is not used frequently in practice, because it can result in high surface temperatures on the inside, resulting in thermal discomfort, especially in hot climates like Phoenix. The maximum inside glass surface temperature in Phoenix during an annual simulation is $56.8^{\circ} \mathrm{C}$ for window 2 and $38.8^{\circ} \mathrm{C}$ for window 3 . Temperatures above $40{ }^{\circ} \mathrm{C}$ are generally considered to be undesirable for the inside glass surface because of thermal discomfort. Above $50{ }^{\circ} \mathrm{C}$ there is risk of injury if the glass is touched. The configuration was used in this study to assess how the various models handle a case with very high absorptance on the inner pane.
The higher thermal mass simulations for Rome show an increase of 1-2\% for Model 5 compared with the baseline model. The ASHRAE 1588 Model 6 results do not vary significantly. The results for triple glazing and room-side low-e do not show larger differences for Models 5 and 6.

\section{Hourly Heating and Cooling CV(RMSE)}

Figure 1 shows the CV(RMSE) values for heating and cooling for all climates, all window types and all models. The highest CV(RMSE) values are for the Simple Window Model 5 (53.5\%) and ASHRAE 1588 Model 6 $(19.6 \%)$. Closer inspection reveals that the largest CV(RMSE) values are almost always for the less dominant form of energy consumption, e.g. the largest $\mathrm{CV}(\mathrm{RMSE})$ for Minneapolis is for cooling and the largest CV(RMSE) for heating is in Phoenix. In Minneapolis the heating energy is $93-96 \%$ of the annual energy, and the cooling energy is only $4-7 \%$. Similarly, for Rome it is 79 $87 \%$ heating energy and $13-21 \%$ cooling. Phoenix is the reverse climate with only $24-31 \%$ heating energy and $67-$ $76 \%$ cooling energy. For this reason, the CV(RMSE) for cooling and heating were weighted by the heating and cooling fractions for the city and window type. This means that the cooling CV(RMSE) in Minneapolis contributes far less to the overall CV(RMSE) than the heating $\mathrm{CV}(\mathrm{RMSE})$. Figure 1 also shows the weighted CV(RMSE) for each case. Table 5 shows the min, max and mean values for the weighted CV(RMSE) for each model. Models 5 and 6 have the highest CV(RMSE) value but require the fewest inputs. All the cases simulated match the ASHRAE Guideline 14 criteria of CV(RMSE) value less than $30 \%$.

\section{Conclusions}

The effect on whole building annual site energy consumption is the largest for Simple Window Model 5 and 1588 Model 6 . The range is $-8.4 \%$ (underpredicted) to $6.0 \%$ (overpredicted) for Model 5 and $-0.1 \%$ to $5.0 \%$ for Model 6. Model 6 almost always overpredicts the energy consumption which is a conservative approach. Model 5 sometimes over- and other times under-predicts energy consumption, which results in a lower mean difference $(1.1 \%)$ for Model 5 compared to Model 6 $(2.8 \%)$. Model 6 and Model 5 require significantly fewer inputs to model a window; up to three values for Model 5 and seven or more for Model 6. If detailed input data is available for the window, models 1-4 all perform quite well with annual energy impact less than $1.6 \%$ and $\mathrm{CV}$ (RMSE) less than $5.5 \%$. In an information-poor environment, where specific glazing coating, gas fill and frame conductance are unknown, Models 5 and 6 have to be used. The uncertainty in the results increases when less data is available. Model 6 should be used if information about the spacer type, number of glass panes and frame type are available. The maximum $\mathrm{CV}(\mathrm{RMSE})$ for this model is $10.6 \%$. If only U, SHGC and optional VT are known, Model 5 can be used with up to $6 \%$ annual site energy uncertainty and up to $27.9 \% \mathrm{CV}$ (RMSE), for the climates, window types and building constructions evaluated in this study. 
The ten-year-old Simple Window Model 5 does not perform any worse with new technologies like room-side low-e surfaces, or for highly insulating triple glazed windows, however the ASHRAE 1588 Model 6 provides more accurate results if additional data is available. Higher thermal mass buildings and absorptive glazings (window 2) do not appear to have a large effect on the uncertainty of the results compared with more standard window configurations and constructions with less thermal mass.

\section{Acknowledgement}

This work was supported by the Assistant Secretary for Energy Efficiency and Renewable Energy, Building Technologies Office, of the U.S. Department of Energy under Contract No. DE-AC02-05CH11231.We acknowledge Simon Vidanovic in helping design the simulations in this study.

\section{Disclaimer}

This document was prepared as an account of work sponsored by the United States Government. While this document is believed to contain correct information, neither the United States Government nor any agency thereof, nor The Regents of the University of California, nor any of their employees, makes any warranty, express or implied, or assumes any legal responsibility for the accuracy, completeness, or usefulness of any information, apparatus, product, or process disclosed, or represents that its use would not infringe privately owned rights. Reference herein to any specific commercial product, process, or service by its trade name, trademark, manufacturer, or otherwise, does not necessarily constitute or imply its endorsement, recommendation, or favoring by the United States Government or any agency thereof, or The Regents of the University of California. The views and opinions of authors expressed herein do not necessarily state or reflect those of the United States Government or any agency thereof, or The Regents of the University of California. Ernest Orlando Lawrence Berkeley National Laboratory is an equal opportunity employer

\section{References}

Arasteh, D.; Kohler, C. and Griffith, B. (2009). Modeling Windows in Energy Plus with Simple Performance Indices. Report LBNL-2804E, Lawrence Berkeley National Laboratory, 2009.

ASHRAE. (2016). Final Report ASHRAE 1588RP. Representative Layer-by-Layer Descriptions for Fenestration Systems with Specified Bulk Properties such as U-factor and SHGC. American Society of Heating, Refrigerating and Air-Conditioning Engineers, Atlanta, Georgia, USA.

Curcija, D.C.; Vidanovic, D.S.; Hart, R.G.; Jonsson, C.J. and Mitchell, R.D. WINDOW Technical
Documentation. LBNL Technical Report. April, 2018.

DOE. (2018). EnergyPlus 9.0.1: Energy Simulation Program. U.S. Department of Energy.

International Code Council. IECC 2006. International Energy Conservation Code: 2006 Edition.

ISO. (2003). "ISO 15099: Thermal Performance Of Windows, Doors And Shading Devices - Detailed Calculations". International Standards Organization.

DOE. (2018). "EnergyPlus Engineering Reference". October 2018.

Huang, J.; Kruis, N.; Lyons, P. and Wong, J. Final Report ASHRAE 1588-RP, Representative Layer-by-Layer Descriptions for Fenestration Systems with Specified Bulk Properties such as U-factor and SHGC. American Society of Heating, Refrigerating and AirConditioning Engineers, Atlanta, 2016.

Klems, J.H. (1993a). A New Method for Predicting the Solar Heat Gain of Complex Fenestration Systems. I. Overview and Derivation of the Matrix Layer Calculation. ASHRAE Winter Meeting, New Orleans, January 1994.

Klems, J.H. (1993b) A New Method for Predicting the Solar Heat Gain of Complex Fenestration Systems. II. Detailed Description of the Matrix Layer Calculation. ASHRAE Winter Meeting, New Orleans, January 1994.

LBNL. (2019a). THERM 7.7 - A PC program for analyzing window thermal performance of fenestration products. Windows and Daylighting Group, Lawrence Berkeley National Laboratory.

LBNL. (2019b). WINDOW 7.7 - A PC program for analyzing window thermal performance of fenestration products. Windows and Daylighting Group, Lawrence Berkeley National Laboratory.

Lyons, Peter;Wong, Justin and Bhandari, Mahabir. A Comparison of Window Modeling Methods in Energyplus 4.0, IBPSA SimBuild 2010, New York.

Ruiz, G., \& Bandera, C. (2017). Validation of calibrated energy models: common errors. Energies, 10(10), 1587.

U.S. DOE. (2018). Residential Prototype Building Models - 2006 IECC.

https://www.energycodes.gov/development/residentia l/iecc models.

Wright, J. L., Barnaby, C. S., Collins, M. R., Kotey, N. A., (2009). Improving Cooling Load Calculations for Fenestration with Shading Devices, final report, ASHRAE Research Project 1311-RP.

Wright, J.L.; Barnaby, C.S.; Niles, P. and Rogalsky, C.J. 2011. Efficient Simulation of Complex Fenestration Systems in Heat Balance Room Models. IBPSA SimBuild 2011, Sydney. 